\title{
Learnings from a Lesson Study in Using Discovery Learning in Teaching the Mean of Grouped Data
}

\author{
Adrian U. Bugay ${ }^{a}$, Jaime G. Caballero ${ }^{b}$, Neil Andrew T. Cacas ${ }^{c}$, Adaiah C. Presto ${ }^{\text {d }}$ Levi E. Elipane \\ ${ }^{a}$ Gen.Juan Castaneda Senior High School, Philippines \\ ${ }^{\mathrm{b}}$ Australian International School, Philippines \\ ${ }^{c}$ Vicente Madrigal Integrated School, Philippines \\ ${ }^{\mathrm{d}}$ Palawan State University, Philippines \\ ${ }^{\mathrm{e}}$ Philippine Normal University, Taft, Manila, Philippines \\ *dapresto@psu.palawan.edu.ph
}

Article History: Received: 10 November 2020; Revised 12 January 2021 Accepted: 27 January 2021; Published online: 5 April 2021

\begin{abstract}
This paper probes, through a Lesson Study, how discovery learning and contextualized problems can be employed in teaching the mean of grouped data. The research lesson was implemented Grade 7 students of a national high school in Calamba City, Laguna, Philippines. Through thematic analysis, three issues emerged from conducting the Lesson Study: (1) making meaning about the data in context fosters students' mathematical understanding; (2) translating 21 st century learning in the classroom with technical topics like the mean of group data can be done by shifting the focal point of the lesson on its importance and applications in life; and (3) identifying the critical points of a lesson is an indispensable process that teachers need to undergo in designing learning activities that promote 21 st century learning and relevant to the demands of the Fourth Industrial Revolution. This study demonstrated how Lesson Study is an effective professional development intervention that allows teachers to view the learning process in a wider perspective, strengthen their skills in designing efficacious lessons, and bring forth change in their teaching practices via reflective stances on lessons.
\end{abstract}

Keywords: Mean of Grouped Data, Lesson Study, Discovery Learning, Contextualized Problem, 21st Century Learning

\section{Introduction}

With the demands of the Fourth Industrial Revolution (4IR), teachers have a crucial role in honing individuals to become highly skilled in dealing with the fast-paced technological changes in the knowledge economy. 4IR poses a set of challenges for teachers to continually seek opportunities for professional growth and engage in activities that can help them improve their teaching practices and enable them to provide learning experiences relevant to the life at present.

Sigwadi [1] described 4IR as the new revolution, which involves machine learning, statistical modelling, Internet of Things (IoT), resulting in reliance on technology for many tasks. Consequently, having a large amount of knowledge and information is not adequate for an individual to meet the demands of 4IR. According to Hussin [2], in order to be successful in the 4IR, individuals need to cultivate a new way of thinking, accompany with a strong skill set, including creativity and capacity to think critically. Thus, students should be empowered to become creative thinkers, critical thinkers and problem solvers - people who can competently apply their new knowledge to complex, novel, and open-ended challenges. This statement supports the importance of promoting 21 st century learning to meet the demands of 4IR.

In the same vein, Maas, Jochim, and Gross [3] asserted that 21st century learning helps students develop a set of skills that extend beyond traditional academic expectations. In a study on the assessment practices in the Philippine higher STEAM (Science, Teachnology, Engineering, Agriculture, Mathematics) Education - those that utilize both traditional and authentic tools and strategies - were categorized as (1) readiness for career or industry, (2) systems to support instruction, and (3) collaborative and reflective processes [4].

The Philippine mathematics education K to 12 Curriculum stipulates that critical thinking and problem-solving as its twin goals for student learning. Hence, mathematics teachers must be translated to 21 st century learning in their classroom effectively. This study aimed to explore how mathematics teachers improve teaching strategies and approaches that can target the critical thinking and problem-solving skills of the studentsby utilizing discovery and contextualized learning. Specifically, a Lesson Study on teaching the mean of grouped data was conducted. 


\section{Literature Review}

\section{Discovery and Contextualized Learning}

One of the innovative strategies that teachers can use for the effective delivery of mathematics instruction is discovery learning. Developed by Jerome Bruner in 1960s, this learning strategy - that has been an enduring theoretical framework that has been informing education researchers - encourages students to participate actively in the learning process. According to Yuliani (2011) as cited by Maarif [5], discovery learning enables the students to discover concepts and principles through observing, classifying, making allegations, explaining, and drawing a conclusion. The concepts in mathematics are not given directly to the students; instead, they are involved in rediscovering them through the process of abstraction [6]. Thus, discovery learning provides opportunities for students to explore information and concepts, connect and assimilate new information to their existing knowledge, determine relationships among ideas, construct new knowledge, and participate in problemsolving.

Various studies have been conducted to explore the use of discovery learning in classroom instruction. Researchers recognized that the implementation of discovery learning methods could improve students' writing and listening skills along with social attitudes score [7,8]. Moreover, studies found out that discovery learning made significant results in improving learners' mathematical analogy skills, motivation for learning math, and mathematics learning outcomes [9,10]. Since discovery learning allows students' full engagement, it also maximizes their learning potential [11].

In addition, teachers can also use contextualized problems in teaching mathematics. Context is defined as a locale, situation, or set of conditions that may influence their learning of the students [12]. In mathematics, context supports students as they solve mathematical problems by providing familiar situations which allow them to try different ways of solving the problem and figure out the mathematical solution [13]. The concept of contextualization is anchored on the idea that students learn best when experiences in the classroom have meanings and relevance in their lives. Although the use of contextualized problems can present some challenges for students, context can lead to meaningful learning as it motivates students to be active in class discussions by asking questions, explaining solutions, and justifying reasons [14]. Further, real-life connections provide a deeper understanding of math concepts and skills [15]. In support of this, Garin, Reyes, Domantay, and Rosals [16] recommended the use of contextualized data in teaching statistics to improve the performance of the students.

\section{Mathematical Knowledge for Teaching (MKT)}

Ball, Thames, and Phelps [17] defined mathematical knowledge for teaching (MKT) as the mathematical knowledge needed to carry out tasks in teaching mathematics. MKT is central to teaching rather than on the teachers. This concept posits that teaching refers to everything teachers must know and do to support students' learning. It is not only about the interactive work of teaching that occurs during class discussions and the other tasks required in that process (e.g., examining the source of the students' incorrect answers), but it also encompasses designing learning activities, preparing and assigning homework, assessing students' performance, and attending to the concerns of parents and students.

Hill, Rowan, and Ball [18] conducted a study that assessed the MKT of teachers and explored how it influences the performance in mathematics of 115 elementary students. The results revealed that the teacherparticipants' MKT positively predicted the students' achievement in mathematics.

Lesson analysis through recorded videos of class discussions was identified as an effective strategy to structure teachers' MKT [19]. This process allows teachers to scrutinize their students' mathematical thinking, look into the students' mathematical difficulties and errors through their statements and reactions, make comparisons between their colleagues' teaching practices and their own, and collectively come up with a model lesson which is more advantageous in teaching the mathematical topics on hand. In addition, Bieda, Cavanna, and Ji [20] identified that Lesson Study is an effective strategy in enhancing practicing teachers' MKT through collaborative inquiry with their peers. Through LS, teachers are given opportunities to contribute and engage in transformative interventions directed towards thedevelopment of their capacities in teaching [21]. It entails that the collective efforts of teachers are necessary for pursuing the development of MKT.

\section{Lesson Study (LS)}

Aside from exploring different strategies that can be used in teaching mathematics effectively, teachers should also engage in activities that can developed their mathematical knowledge for teaching (MKT).

Lesson Study (LS) is originally a common practice of Japanese teachers to work together in improving their knowledge and skills about the teaching and learning process. Even outside Japan, it is considered one of the innovative approaches for in-service training that allows teachers to collaboratively reflect on their practices inside 
the classroom and design a lesson that addresses the learning needs of their students. According to Fujii [22], through LS, teachers are involved in the following processes: formulating the research theme based on the gap between the students' current state and the long-term educational goals for their learning and development; planning a "research lesson" for a specific academic content which will address the research theme; observing and collecting data with the other members of the planning team, staff members from across the school, and an outside knowledgeable other while one team member teaches the research lesson; sharing of data from the lesson to illuminate student learning, disciplinary content, lesson and unit design, and broader issues in teaching and learning; and documenting the whole process to consolidate and carry forward learnings, as well as new questions for the next cycle of LS.

The introduction of LS in various parts of the Philippines allowed the Filipino teachers to experience a different way of looking into a lesson. This experience enabled them to see the challenges and reformations that they need to undertake to teach mathematics so that students will be given opportunities to explore and discover mathematical concepts [22]. Elipane [23, 24] opines that LS, as a professional development intervention, has the potential to improve mathematics education in the country. However, he further points out that the differences between Japan and the Philippines indicate the need for detailed investigations on the cultural and institutional conditions to effectively incorporate LS in the roots of the Philippine educational system.

With 21st century learning and MKT in mind, the researchers devised a research lesson that incorporates discovery learning and contextualized problems to maximize the students' engagement in the teaching and learning process involving the mean of grouped data - a topic that the researchers find very useful in/for the 4IR.

\section{Methodology}

The positive impact of LS in the engagement of teachers and students in the teaching and learning process encouraged the class composed of 10 graduate students of Philippine Normal University (PNU) under the program Doctor of Philosophy in Mathematics Education to conduct an LS first-hand. They were all enrolled in the course: Contemporary Curricular Perspective in Mathematics Education (MATH ED 803) during the third term of the Academic Year 2019-2020.

In conducting this LS, the research underwent three phases: (1) planning phase, (2) implementation phase, and (3) post - discussion phase.

\section{Planning}

The researchers - consisted of a group of four graduate students from the class - had a three-week preparation for the research lesson. During the first week, they selected the topic based on the learning competencies in the Grade 7 Mathematics curriculum guide, taking into consideration the current lesson of the target learners at the time of the scheduled implementation. We agreed that the topic would be about the mean of grouped data. In the second week, the researchers discussed the teaching strategy, which would be employed in the research lesson, as well as the possible flow of the class discussion. With the 21 st century learning in mind, we decided to apply discovery learning in teaching the mean of grouped data. Then, we started writing the plan for the research lesson. The learning objectives and the projected time were taken from the teaching guide, learner's materials, and curriculum guide for Grade 7 Mathematics. By the third week, the research lesson was finalized in the form of a semi-detailed lesson plan and the needed instructional materials and worksheets were in order.

\section{Implementation}

On March 9, 2020 at 1:00 p.m., the research lesson was implemented to 33 (15 male and 18female) Grade 7 students of Eduardo Barretto Sr. National High School located in Calamba City, Laguna. The students were purposively selected based on the availability of their schedule, their section, and their willingness to participate in the study. It was observed by four Mathematics teachers of the aforementioned school, nine graduate students from Philippine Normal University (which included the researchers), the school principal, and the researchers' professor (who is the last author of this article).

The teacher started the class discussion by presenting a contextualized problem about the mean of ungrouped data to activate the prior knowledge of the students and prepare them for the topic intended on that day. Since Laguna is considered as the "Resort Capital of the Philippines" with more than 700 hot spring resorts [25], the contextualized problem was about the number of resorts visited by 20 grade 7 students of Mr. Lazaro. The data in the problem was presented using a table (see Figure 1), which caused some confusion among the students. 


\section{Mr. Lazaro, a Mathematics teacher in Eduardo Barreto National High School conducted a survey to know the number of resorts that his 20 Grade 7 students already visited in Laguna. Then, he presented the data to his class and asked one of his students, Crisostomo to compute the mean of the data. The table below shows the data that Mr. Lazaro collected.}

\begin{tabular}{|c|c|}
\hline No. of resorts visited & $\begin{array}{c}\text { Frequency } \\
\text { (No. of students) }\end{array}$ \\
\hline 0 & 2 \\
\hline 1 & 2 \\
\hline 2 & 3 \\
\hline 3 & 3 \\
\hline 4 & 6 \\
\hline 5 & 2 \\
\hline 6 & 1 \\
\hline 7 & 1 \\
\hline Total & $\mathbf{2 0}$ \\
\hline
\end{tabular}

Figure 1.The contextualized problem used in the introductory activity

Out of 33, 24 students had difficulty understanding the problem; they just added the values under the column for the number of students and divided it by 8 to get the mean. After some clarifications given by the teacher, they were able to answer the problem correctly.

Then, the teacher proceeded by providing a similar problem with a larger set of data. The teacher handed worksheets and let the students fill out the frequency column. After the students grouped the given data into class intervals, the teacher asked them if there were unfamiliar symbols in the table that they observed.

The symbol for class mark $(X m)$ was one of the symbols that they mentioned. The teacher let the students work in groups to think about how the class mark can be determined. After doing so, the students shared their answers and explanations. And then, the teacher asked the students some questions which guided them in solving the problem.

Afterwards, the teacher instructed the students to identify the formula for the mean of grouped data based on the process that they did in the activity. This part of the lesson showed the researchers' objective to address the 21 st century skills of the students through discovery learning which allows learners to participate actively in the learning process and maximize their learning potential by processing information, making connections, and drawing conclusions.

Upon establishing the relationship of the student's prior knowledge about computing the mean of ungrouped data and their present knowledge of computing the mean grouped data, the teacher provided another contextualized problem that they solved individually. It was observed that the students answered the said problem quickly, and most of them were able to come up with correct answers.

\section{Post-lesson Discussion}

After the execution of the research lesson, the observers, including the researchers, gathered for the post-lesson debriefing. First, the researchers were given an opportunity to share their insights and reflections about the LS that they conducted. Then, the observers gave their comments, suggestions, and recommendations on how the research lesson could be improved. The whole post-lesson discussion lasted for about an hour.

\section{Results and Discussions}

Upon synthesizing the commentaries given by the observers during the post-lesson conference and their whole experience in conducting this LS, the researchers were able to observe three emerging themes which could contribute to the professional development of teachers: (1) making meaning about the data in context fosters students' mathematical understanding; (2) translating 21st century learning in the classroom with technical topics like the mean of group data can be done by shifting the focal point of the lesson on its importance and applications in life; and (3) identifying the critical points of a lesson is an indispensable process that teachers need to undergo in designing learning activities which promote 21 st century learning and relevant to the demands of the Fourth Industrial Revolution (4IR). 


\section{Privileging Numbers or Data in Context in Problem-Solving or Data Analysis Supports Deeper Mathematical Understanding of Students}

In the introductory activity, the researchers decided to present the data using a table (see Figure 1) for the students to think about how they can use the process of computing for the mean of ungrouped data given data in a different form. As a result, only nine students out of 33 were able to understand the data in the table - they multiplied the values under the two columns and divided the sum by 20 to get the mean correctly. On the other hand, 24 students got the sum of the values under the column for the number of students and divided it by 8 . To direct the students, the teacher asked the class, "What is the meaning of zero for the number of resorts and two for the number of students?" A student answered, "There are two students who haven't visited any resort." Through this, the students were able to make meaning out of the data in the table and figure out how to solve the mean correctly. As a result, 20 out of the abovementioned 24 students changed their solution. At the end of the activity, 29 students out of 33 were able to find the mean of the given data correctly.

During the post-conference, one of the observers said, "I would like to commend the group for using localized problems in their lesson on which students can really relate to." It was evident that at the onset of the introductory activity, the students were well-engaged when they eagerly answered the question of the teacher about the number of resorts that they already visited in Laguna which is also the focus of the problem presented to them. Another observer appreciated the use of contextualized problems in the lesson, but she addressed the confusion encountered by the students during the first activity by asking the researchers, "What kind of students were you considering when you planned this lesson?" She added, "That could be a factor why students had difficulties in doing the activity." One of the researchers answered, "We anticipated that they are fast learners since we were told that they are from a science class."

The comments given by the observers showed the importance of using contextualized problems in teaching mathematics, specifically in introducing formulas in context [26]. The familiar situations provided by the context support students in exploring different ways of solving the problem [12]. Teachers can employ contextualized problems to elicit students' engagement in learning and give them a clear picture about the connection of their lesson in real life which can lead to deeper understanding of math concepts and skills [15]. On the other hand, their comments also emphasized that it is essential for teachers to consider the nature and learning capacity of students in crafting an introductory activity which involves a contextualized problem. The difficulty that students experienced in understanding the contextualized problem in the introductory activity shows that the opennesss of contextual problems gives way to different interpretations, and also misconceptions or misunderstandings among students [14].

In response to the challenge faced by the teacher and students during the first activity, the researchers' professor suggested, "Why not allow the students to describe the general characteristic of the data before letting them solve for the technical and analytical aspect of the table?" This suggestion highlighted the importance of allowing the students to make sense of the context and data in the problem before assigning them to solve it. Teachers can establish an appropriate link between the context and the mathematical ideas by processing students' interpretations of the context [14]. Moreover, it is essential to help the students see the relation of the informal mathematics that they do in their day-to-day lives with the formal mathematics ideas that they are learning at school [26].

To carry out this teaching task, teachers need a deep understanding of the subject matter; and also, MKT which enables them to analyze and process the mathematical ideas of the students as they construe and solve the contextualized problem [27].With MKT, teachers would be able to come up with thought-provoking questions that can help students have a comprehensive understanding of the problem, and further, see the importance of the mathematical concept involved in the problem through the context [14]. In the implementation of the research lesson, the teacher should have used the contextualized problem not just as a springboard to introduce the lesson about the mean but also as a medium to let the students view the mean as a tool for describing and making sense of a data set and as a mathematical algorithm for solving problems and making sound decisions.

One reflection was that, in writing a contextualized problem that can be used as an introductory activity for a lesson, teachers should not only target to provide a familiar context to the students, but also to seamlessly tie the context with the mathematical concept involved in the lesson.

\section{Different Mathematical Organizations or Topics Require Different Techniques or Strategies}

One of the findings that emerged from conducting this LS is the mismatch between the teaching strategy employed (i.e., discovery learning) and the nature of the lesson. Although discovery learning has been identified as effective strategy in improving students' mathematical learning outcomes in geometry [9] and grade school mathematics [10], it did not serve as appropriate in teaching the lesson about the mean of grouped data. Some 
mathematical topics can be taught better with other teaching strategies besides discovery learning. Wardono et al. [28] identified that generative learning assisted by teacher aids is more effectual in increasing students' mathematical written communication ability than discovery learning.

In the second activity, the students were given another word problem, which was related to the prior contextualized problem presented to them. The students were asked to find the mean of the number of resorts visited by 50 grade 8 students of Mr. Lazaro. There were more values involved in the data compared to the first activity, and these were presented through listing.

Two tables were provided in the worksheet to guide the students solve the given problem using the mean of grouped data. In the first table, the students grouped the values in the data into class intervals by tallying and writing the frequency. They were given 3 minutes to do this. The students did not encounter any difficulty in completing the first table.

After this, they were told to transfer the frequency of each class interval in the second table. The teacher asked them, "How do you think can we determine the class mark (Xm) of each class interval?" Then, they were instructed to work together by group in answering this question. During the discussion, one student answered, "The class mark of the class interval 22-32 is 27 because it is the result of dividing the sum of 22 and 32 by two. "It turned out that all the groups have the same explanation on how they determined the class mark of the class interval that they have chosen. Because of this, the teacher tried to direct the students to the concept that the class mark is the value that best represents the values in a class interval. In addition, she also attempted to clarify that aside from identifying this through dividing the sum of the highest value and the lowest value in the class interval by two, it can also be determined by considering the middle value in the class interval and computing the mean of the values in the class interval. This action of the teacher dragged the time for the development of the lesson. According to one of the observers, there were some questions thrown by the teacher which were not necessary for teaching the lesson's technical aspects.

The lesson continued with the students completing the needed values in the second table (see Figure 2). The teacher guided the students in solving for the mean. Then, the students were given a task by group to determine the formula for the mean of grouped data based on the process that they did in solving the given problem. All the groups were able to determine the formula for the mean of grouped data correctly - albeit via guesswork and following cues from the teacher.

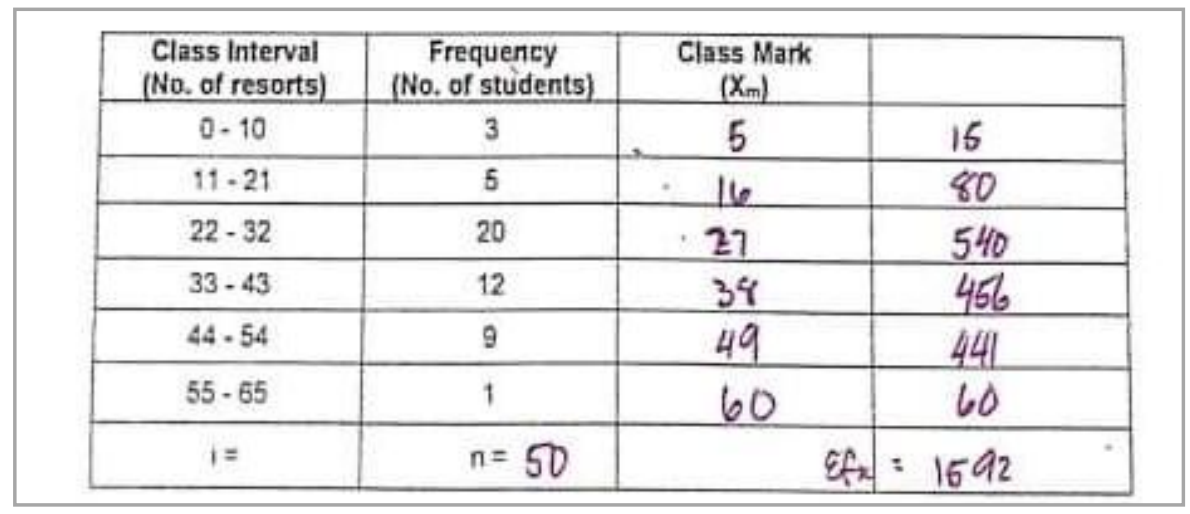

Figure 2.Sample response for the second table in the second activity

During the third activity, the students were once again given a worksheet containing a problem about the daily number of visitors in Rizal Shrine during January and February. Out of 33 students, 26 were able to solve the mean of the grouped data in the problem correctly. These students

The whole lesson took 1 hour and 22 minutes, which was longer compared to what the researchers had in mind during the planning period. One observer commented, "The lesson is very realistic, but it is too long." This could be attributed to the amount of time used in letting the students determine the process of getting the class mark and identify the formula for solving the mean. According to the researchers' professor, "How important is it for students to find out the class mark on their own when this is very technical? Technical things are better taught directly." Consequently, in mathematics, there are things - such as arbitrary technical algorithms or procedures that need to be taught directly, while there are mathematical concepts that may be better explored or discovered [29]. This led to the researchers' reflection that the teachers' capacity to create productive instructional tasks/episodes in the classroom is founded on pedagogical knowledge, subject matter knowledge, and continuous professional development [30]. Accordingly, this ability can be further developed by engaging in LS [22]. 
Through LS, the researchers were able to have a clearer view of how to translate 21 st century learning in the classroom, especially when teaching technical topics.

First, it is important for teachers to look into the nature of the topic before selecting an appropriate teaching strategy that promotes 21 st century learning.

Second, when teaching technical topics like the mean of grouped data, teachers should give emphasis on describing the data, interpreting the computed mean value, and knowing when it can be used in real life.

Third, teachers may incorporate the use of technology in teaching technical topics as a way of developing $21 \mathrm{st}$ century skills in the 4IR. After presenting the process of computing the mean of grouped data manually, the use of Microsoft Excel and Statistical Package for the Social Sciences (SPSS) in computing the mean of large data may be introduced to the students. The use of software applications for data analysis like PSPP in teaching statistics has been found to be effective in increasing students' interest toward the subject and academic performance [31].

Lastly, teachers can assign students some authentic tasks through project-based learning in statistics which would allow them to explore the applications of what they have learned about the technical topic in the real world [32]. As for the mean of grouped data, the students can determine an issue or phenomenon in their school or community, which calls for the mean's computation. After gathering the data, they would be given a choice to decide on how they will compute the mean of their data. The final output could be in the form of a written report.

Through choosing the appropriate strategy, shifting the emphasis of the lesson to what is necessary, incorporating the use of technology, and giving authentic tasks to the students, teachers can translate 21 st century learning in their classroom even when they are teaching technical topics like the mean of grouped data.

\section{Identifying the Critical Points of the Lesson}

The highlights of the research lesson utilized in this LS were the development of the concept of class mark and the derivation of the formula for the mean of grouped data. These were also evident during the implementation of the research lesson in which the concept of the class mark was given emphasis by the teacher. A large part of the time for class discussion was used for discovering the class mark and the formula for the mean of grouped data.

Although the researchers intended to target the critical thinking, collaboration, and communication skills of the students during the development of the lesson with discovery learning, they missed to stress the significant aspects of the lesson. In response to this, the researchers' professor advised them, "Be mindful of the critical points for the lesson and focus on them." This comment rectified the importance of identifying the critical points of a lesson during the planning period. By identifying the critical contents of a topic, the teacher would be able to communicate effectively to the students why the new learning is important, how it can be connected to their prior learning or experiences; and when it can be beneficial or necessary [33].

With this LS, the researchers rationalized that knowing the critical points of a lesson empowers teachers in designing effective and appropriate learning tasks, and also in processing the possible statements and reactions of the students out of these tasks. At the onset of lesson planning, the key concepts and skills that the students need to understand and acquire in a particular topic should be clear to the teacher [34]. As for their research lesson, the focus should have been on describing and making sense of the given data, interpreting the computed value, determining the implication of the computed value, and knowing its importance and applications in real life rather than discovering technical terms, deriving the formula and understanding the process of solving.

During the planning period, the researchers should have considered these critical points in order to come up with learning activities that would strengthen the understanding of the students about the importance and applications of the mean of grouped data. Since the mean is not only an important concept in statistics but also a significant concept in the daily life of informed citizens, students need to develop a full conceptual understanding of it. That is, they should view the mean as an instrument that they can use for describing and analyzing data. Moreover, the results of using this tool can be utilized as a basis for solving problems and making sound judgments.

Teachers should determine and focus on the critical points of a lesson in order to provide learning activities that promote 21 st century learning and relevant to the demands of the 4IR.

\section{Conclusion}

Throughout this whole research process, the beauty and power of LS were on full display. The challenges during the planning period, difficulties encountered by the teacher and students in the implementation of the lesson, and the meaningful comments and suggestions given by the observers during the post-lesson conference, allowed the researchers to have realizations regarding lesson planning and teaching practices. 
An in-depth understanding of the subject matter and its nature allows teachers to identify the appropriate teaching strategy, develop contextualized problems that seamlessly tie the context and concept involved in the lesson, and craft learning activities aligned with the critical points of the lesson. Aside from knowing the subject matter fully, it is also important for teachers to know how to teach this content, i.e., carry out teaching tasks effectively and process students' statements and reactions during class discussions efficiently.

Thereupon, LS offers teachers an opportunity to work collaboratively in investigating practices inside the classroom, rediscover effective ways of teaching, develop skills in designing lessons relevant to the learning needs of the students, and further enhance their MKT.

\section{Acknowledgement}

The researchers would to express their gratitude first and foremost to the Lord God Almighty for His unending grace, mercy, and love and to their professor, Dr. Levi E. Elipane for giving them the opportunity to experience the whole process of LS

\section{References}

Sagwadi, L. (2020). Data science and the fourth industrial revolution (4IR). University of the Western Cape.

Hussin, A. (2018). Education 4.0 made simple: Ideas for teaching. International Journal of Education \& Literacy Studies, 6(2), 92-98.

Maas, T., Jochim, A., \& Gross, B. (2018). Mind the gap: Will all students benefit from 21st century learning? Center on Reinventing Public Education. .

Sarmiento, C., Morales, M. P., Elipane, L. \& Palomar, B. (2020). Assessment practices in Philippines higher steam education. Journal of University Teaching \& Learning Practice, 17(5).

Maarif, S. (2016). Improving junior high school students' mathematical analogical ability using discovery learning method. International Journal of Research in Education and Science, 2(1), 114-124.

Simamora, R., Saragih, S., \& Hasratuddin. (2019). Improving students' mathematical problem solving ability and self-efficacy through guided discovery learning in local culture context. International Electronic Journal of Mathematics Education, 14(1), 61-72.

Hanafi. (2016). The effect of discovery learning method application on increasing students' listening outcome and social attitude. Dinamika Ilmu, 16(2), 291-306.

R. Prawerti. (2014). Learning method in teaching writing skill viewed from the students' creativity. Unpublished Thesis, Sebelas Maret University Surakata.

In'am, A. \& Hajar, S. (2017). Learning geometry through discovery learning using a scientific approach. International Journal of Instruction, 10(1), 55-70.

Yurniwati, L. \& Hanum (2017). Improving mathematics achievement of Indonesian 5th grade students through guided discovery learning. Journal on Mathematics Education, 8(1), 77-84.

SEI-DOST \& MATHTED. (2011). Mathematics framework for philippine basic education. SEI-DOST \& MATHTED, Manila.

DepEd. (2016). K to 12 mathematics curriculum guide. DepEd, Manila.

Valenzuela, H. (2018). A multiple case study of college-contextualized mathematics curriculum. MathAMATYC Educator, 9(2), 49-55.

Widjaja, W. (2013). The use of contextual problems to support mathematical learning. IndoMS-JME, 4(2), 151159.

Benson-O'Connor, C., McDaniel, C., \& Carr, J. (2019). Bringing math to life: provide students opportunities to connect their lives to math. Networks: An Online Journal for Teacher Research, 21(2), Article 3.

Garin, R., Reyes, R., Domantay, G., \& Rosals, J. (2017). Contextualized and localized teaching as a technique in teaching basic statistics. Asia Pacific Journal of Education, Arts and Sciences, 4(1), 62-67.

Ball, D., Thames, M., \& Phelps, G (2008). Content knowledge for teaching what makes it special? Journal of Teacher Education, 59(5), 389-407.

Hill, H.C., Rowan, B., \& Ball, D.L. (2005). Effects of teachers' mathematical knowledge for teaching on student achievement. American Educational Research Journal, 42(2), 371-406.

Baki, M. (2016). The development of mathematical knowledge for teaching of mathematics teachers in lesson analysis process. European Journal of Educational Research, 5(4), 165-171.

Bieda, K., Cavanna, J., \& Ji, X. (2015). Mentor-guided lesson study as a tool to support learning in field experiences. Mathematics Teacher Educator, 4(1), 20-31.

Elipane, L. (2013). Developing deep mathematics teaching discourse through research lessons. The 14th International Conference on Education Research: Future Education Design for All, 286-292.

Fujii, T. (2016). Designing and adapting tasks in lesson planning: A critical process of lesson study. ZDM.

Elipane, L. (2017). Introducing lesson study as a professional development model in the islands of the Philippines. Advanced Science Letters, 23(2), 1126-1129. 
Elipane, L. (2012). Towards the embodiment of competency standards: Incorporating the elements of lesson atudy in the pre-service mathematics teacher education in the Philippines. The Asia-Pacific Education Researcher, 21(2), 365-374.

Bation, P. (2012). Five things you didn't know about Laguna. Retrieved April 1, 2020 from https://www.dotproperty.com.ph/

Quintero, A. \& Hector, R. (2016). Math makes sense!: A constructivist approach to the teaching and learning of mathematics. Imperial College Press.

Hill, H. et al. (2008). Mathematical knowledge for teaching and the mathematical quality of instruction: An exploratory study. Cognition and Instruction, 26(4), 430-511.

Wardono et al. (2020). Comparison between generative learning and discovery learning in improving written mathematical communication ability. International Journal of Instruction, 13(3), 729-744.

Hewitt, D. (1999). Arbitrary and necessary part 1: A way of viewing the mathematics curriculum, For the Learning of Mathematics, 19(3), 2-9.

Matic, L. (2019). The teacher as a lesson designer. ceps Journal, 9(2), 139-160.

Sto. Tomas, M. et al. (2019). The use of PSPP software in learning statistics. European Journal of Educational Research, 8(4), 1127-1136.

Yuli, T. et al. (2018). Effectiveness of project based learning in statistics for lower secondary schools. Eurasian Journal of Educational Research, 75, 197-212.

Senn, D. et al. (2014). Identifying Critical Content: Classroom Techniques to Help Students Know What is Important. Learning Science International: United States of America.

Brahier, D. (2016). Teaching Secondary and Middle School Mathematics (5th ed.). Routledge: New York, USA. 